\title{
Knowledge Association Method in the Teaching of Professional Basic Courses
}

\author{
Kehu $\mathrm{Xu}^{*}$ \\ Dept. of Weapons and Control \\ Army Academy of Armored Forces \\ Beijing, China
}

\author{
Guosheng Wang \\ Dept. of Weapons and Control \\ Army Academy of Armored Forces \\ Beijing, China
}

\begin{abstract}
In view of the wide range of mathematical knowledge, strong systematicness and theorization and the difficulty in resolving the teaching difficult points involved in the course of modern control theory, the association teaching method is carefully designed according to the relevancy of knowledge and the progressive principle of human mastering knowledge such that it is easy to resolve the teaching difficult points and grasp the teaching emphasis. The teaching practice shows that the teaching effect is greatly improved by applying the knowledge association teaching method reasonably.
\end{abstract}

Keywords—knowledge association method; professional basic course; difficulties resolving; course characteristics

\section{INTRODUCTION}

Based on control theory and by means of the computer, automatic control technology has solved a series of high-tech problems. It is playing an increasingly important role in the development and innovation of scientific and technological modernization. There is a great demand for professionals in related subjects so that many engineering colleges in our country have majors related to "automation", and offer courses of Modern Control Theory or Linear System Theory to undergraduates and postgraduates. But how to teach and learn the course well has always been a difficult problem for some teachers and students. The main reason is that we failed to grasp the characteristics of the course and adopt appropriate teaching methods. Through many years of teaching practice, I believe that as long as we fully grasp the characteristics of the course, proceed from the perspective of system theory, integrate the course into the corresponding knowledge system, and associate the knowledge of the course with the knowledge of the relevant courses, we can clear the way of thinking, resolve the difficulties and make the teaching process easier.

\section{The Necessity OF THE ApPLICATION OF KNOWLEDGE AsSOCiation MEthod IN THE TEACHING OF PROFESSIONAL \\ BASIC COURSES}

Learning, especially basic courses and professional basic courses in science and engineering, is very hard work in most cases, and there is not much pleasant ingredient. To accomplish these learning tasks, it is impossible to rely solely on the drive of learning interest (which does not exist in many cases), but also on external pressure (which force us to learn for graduation), perseverance and efforts of oneself. More importantly, it needs the correct learning methods and teaching methods that can properly reduce the difficulty of learning.
Although the proper teaching method can't reduce the difficulty of the course itself, to a certain extent, it can solve the difficulty, just like taking a ladder in front of the cliff leading to the difficult knowledge, which can help the students to complete the learning task smoothly. Knowledge association method can take on this important task.

The so-called knowledge association teaching method is to expand the basic concepts, principles and methods grasped by previous learning (such as basic course learning) into the concepts, principles and methods of current learning (such as professional basic course learning), and lay a foundation for understanding and mastering the problems that will be encountered in subsequent learning (such as professional course learning). This idea is very in line with the characteristics of the professional basic course as a link between the basic courses and the professional courses[1]. How to let students combine basic knowledge with practical application is the main purpose of professional basic course teaching.

The knowledge in any subject area is systematic. In a scientific professional training plan, the curriculum design, the selection of teaching materials and contents, and the arrangement of curriculum schedule should be based on the principle of transition from general knowledge to professional knowledge. If we can use systematic viewpoints and methods to teach and learn in accordance with the principle of progressive knowledge in teaching activities, it will reduce the strangeness of new knowledge, make students associate, give them a familiar feeling, thereby reducing the difficulty of teaching.

\section{ANALYSIS OF THE COURSE CHARACTERISTICS OF MODERN CONTROL THEORY}

Modern Control Theory (mainly linear system theory) is an important professional basic course of Control Science and Engineering in our college. It is the basis of studying the follow-up courses such as Tank Artillery Control System, Tank Fire Control System and other modern control theory and control technology. So it plays a bridge and basic role in basic courses and professional courses. On the one hand, its research object is not a specific control system, but some common problems in a certain kind of control objects. It not only has many new concepts and principles to understand and master but also uses a lot of modern mathematical knowledge in the analysis of the problem. It has a strong theoretical background 
and the characteristics of basic courses[2]. On the other hand, its research content is more concrete than the general basic courses, has a strong engineering background, and has also the characteristics of professional courses. So the students often feel difficult when they study, and the teachers do not feel relaxed when they teach. If we can accurately grasp the following characteristics, we can handle it with ease.

- First, concepts are numerous and abstract. Although it is in line with the Principles of Automatic Control (part of classical control theory), and in a certain sense is the continuation of the Principles of Automatic Control, it has many new abstract concepts[3], such as state space, controllability, observability, Lyapunov stability, state feedback, state observer, functional, functional extremum and so on. In particular, Lyapunov stability is composed of a group of nearly 10 progressive, difficult to understand, confusing abstract concepts and some judgment criteria. It is not easy to learn independently and to really understand and master them.

- Second, the theory is very strong. This course is full of propositions, theorems, inferences, algorithms and criteria from beginning to end. It is mostly expressed by matrix theory, differential equation and calculus knowledge. If a person without relevant professional knowledge takes a look at the textbook, he is likely to consider it as a quasi-mathematical textbook. It is easy to make them feel embarrassed and lose most of their confidence at the moment of learning for those students who do not have a solid foundation in mathematics, especially those who have a certain degree of fear in mathematics. In addition, this course also involves some new mathematical knowledge, such as functional and its extreme value knowledge, matrix differential equation (Riccati equation), etc. This knowledge is enough to make the general students feel afraid, which is also the crux for the general students to perform poorly when they learn relevant knowledge.

- Third, the research object is complex. Modern control theory comes into being in response to the control requirements of modern industrial processes and practical systems in many fields, such as aviation and aerospace. These systems are usually very complex, with the characteristics of multiple inputs multiple output (MIMO) and high order, and often include the characteristics of multi-variable coupling and nonlinearity. This will involve some unique learning content, such as input-output decoupling.

- Fourth, the research methods are different from classical control theory. Different from the classic frequency domain method, such as transfer function, root trajectory and frequency characteristic, adopted by classical control theory for single-input single-output (SISO) linear time-invariant systems, modern control theory is based on state space description in time domain, and mainly uses state space method (time domain method) to conduct qualitative and quantitative analysis of the system from many different aspects in order to achieve desired control effect.

\section{ApPliCATION OF KNOWLEDGE AsSOCiATION METHOD IN THE TEACHING OF MODERN CONTROL THEORY}

\section{A. Strengthen conceptual understanding and turn abstract into the concrete}

The concept is numerous and abstract, which is a major feature of Modern Control Theory. And on the surface, most of these concepts are not organically related to what students have learned before. How to make students understand and accept abstract noun concepts in a relatively short period of time has many ways and means, one of which is "turn abstract into the concrete."

For example, "state space description (or state space expression)" is the most basic and core mathematical model in the course of Modern Control Theory and it is the basis for the later analysis and design system of the curriculum. But the concepts involved are more abstract and difficult to understand. When teaching, you should first take human beings as a natural biological system for example. In our daily life, in order to accurately describe a person's situation, we often talk about how people's "mental state" and "physical state" are, then similarly, "state" can also be used to describe a general system. The performance of the system may be different at different times, so the state is the variable of change, that is, the state variable. Just as changes in the external environment can cause changes in mental and physical states and then respond accordingly, the input of the system will also cause changes in the state of the system (the equation of state, which characterizes the relationship between the changes), and make corresponding responses (the output of the system changes, and the output equation characterizes the relationship between the changes). By clearly describing the changes of these two levels, we can basically grasp the operation of the system, so we call it the model - state space description of the system. Usually, it is difficult for students to understand that the same system will have different state space expressions. On this point, I will give an example of life: different medical experts diagnose the same critically ill patient and check their physiological indicators from different aspects, but the final diagnosis will be the same. Similarly, different systems engineers will describe the same system from different perspectives, and get different system models--state space expressions. However, since different model forms can represent the same system, there must be some equivalent relationship between them (which can be converted to each other by linear transformation), just as in the same vector space we learned in the basic course Linear Algebra, any two maximally linear independent groups are equivalent. According to this way of thinking, students generally reflect easy to understand and remember.

\section{$B$. Strengthen the connection of knowledge and methods between courses to make it easier}

When teaching new content, especially difficult content, teachers should be good at strengthening the connection of knowledge between courses[4], looking for the "bridge" of transition between new and old knowledge, and try to bring out new problems from students' existing knowledge That is to say, teachers' speaking should induce students' thinking, make students' thinking in a positive state, guide students to develop new knowledge from existing old knowledge or draw new 
conclusions from the analysis and observation of the results of simulation experiments, and then master new knowledge and acquire new skills. For example, "linear quadratic optimal control" in this course is a recognized difficulty. If you don't treat it with awe, there will be a situation where the teacher can't teacher clearly, and the students can't understand. But if the instructor can have a profound theoretical foundation, he can grasp the essence of the problem, that is, the optimal control (dynamic optimization) is to use the variational method to get the extremum of the functional. By comparing with the solution of function extremum (static optimization) in calculus and corresponding the process of solving functional extremum in optimal control with the necessary conditions of function derivative, partial derivative and extremum in higher mathematics, he can explain the concept of the functional clearly, and easily get the necessary conditions for functional to get extreme value - Euler equation and boundary conditions.

Similarly, the state space equations of modern control theory and the transfer function of the automatic control principle, the time domain stability of modern control theory and the frequency domain stability of the automatic control principle, etc., can all be extended by basic concepts and basic principles. Through step-by-step guidance and deepening the content of the new contact curriculum, a gradual and smooth transition model between old and new knowledge is established. Students generally have a familiar feeling when they study and the difficult content is also easy to understand and impressive.

\section{Strengthen the connection of follow-up courses and turn them into concrete ones}

Learn useful skills and practical knowledge is what most students expect. However, the knowledge of professional basic courses is often people's abstraction of a kind of concrete problems in production and life. They are general theories with universal practicability and idealization from specific problems Some students think what I have learned can't be used in practice, so the desire to learn well is not strong. If we combine engineering examples when teaching basic theories[5], turn general knowledge into concrete knowledge and combine rational knowledge with perceptual knowledge, take the path of "theory-practice-theory" and let basic concepts and principles "fall to the ground", student's interest and enthusiasm in learning will be greatly stimulated.

For example, the "Inverted Pendulum System", which is a multivariable, fast nonlinear and naturally unstable system with a strong engineering background. It is similar to biped robot, rocket flight control, attitude control of communication satellite and stability of various servo platforms. When new control theories and methods appear, the inverted pendulum can be used to verify their correctness and practicability and to compare various methods quickly, effectively and vividly. Therefore, the inverted pendulum device is recognized as a typical physical model in the teaching and scientific research of control theory and the inverted pendulum experiment has become a necessary experiment for the control engineering in many colleges and universities. However, at present, our automatic control laboratory has only one single inverted pendulum experimental equipment (basically only for "speaking" experiments) and lack of experimental equipment and contents related to new knowledge and technology, such as "two-stage inverted pendulum". Practice teaching and theory teaching is not well connected, and the two teaching content is often out of touch, which will affect students' understand of basic knowledge and mastery of Engineering technology.

\section{SUMMARY}

Basic knowledge is the "source" and "root" of the whole subject professional knowledge system, and the first link of the "knowledge chain". Only on this basis, basic professional knowledge can continue and will not become water without source and a tree without a root. Therefore, in teaching, in addition to educating students to establish a correct learning attitude and enhance learning confidence, teachers must also have a systematic view to guide students to master system knowledge and help them to build the knowledge structure. Teachers should actively adopt the knowledge association method to train students' systematic thinking, progressive thinking and innovative thinking, and improve their ability to analyze problems.

The professional basic course is based on a basic course and supports professional course. We should consciously apply the knowledge association method in the teaching; otherwise, the professional basic course will not play the role of connecting the preceding and the following. To achieve this goal, not only require students lay a solid foundation, thoroughly understand the basic concepts and principles to provide the necessary conditions for knowledge association method, but also require teachers have a deep theoretical foundation and systematic subject knowledge and put a lot of enthusiasm in teaching.

\section{REFERENCES}

[1] Zhu Chang'an. "Relations between different courses and teaching by association-A discussion of teaching methods for fundamental specialized courses,” Education and modernization, vol. 4, pp. 29-32, 2001. (In Chinese)

[2] Wei Minhong. Li Suwen, Zhu Xuan, Dou Dezhao, Shao Fen. "Research on the Teaching Method of Modern Control Theory," Journal of Huaibei Normal University(Natural Science), vol. 37, pp. 92-96, September 2016 (In Chinese)

[3] He Zhen. "On the teaching method of non-electricity specialty control theory course" Journal of Nanchang College of Education, Vol. 27, pp. 56-57, 2012. (In Chinese)

[4] Yan Maode, Ke Wei, Yang Panpan. "Reform and Construction Practice of Curriculum Teaching for Modern Control Theory," Education Teaching Forum, No. 17, pp. 109-111, 2017. (In Chinese)

[5] Teng Qingfang. "Exploration and Practice on Teaching Reform for the Curriculum of Modern Control Theory” Journal of Lanzhou Jiaotong University, Vol. 33, pp. 156-159, October 2014. (In Chinese) 